\title{
Involvement of plant endogenous ABA in Bacillus megaterium PGPR activity in tomato plants
}

\author{
Rosa Porcel ${ }^{1 *}$, Ángel María Zamarreño², José María García-Mina² and Ricardo Aroca ${ }^{1}$
}

\begin{abstract}
Background: Plant growth-promoting rhizobacteria (PGPR) are naturally occurring soil bacteria which benefit plants by improving plant productivity and immunity. The mechanisms involved in these processes include the regulation of plant hormone levels such as ethylene and abscisic acid (ABA). The aim of the present study was to determine whether the activity of Bacillus megaterium PGPR is affected by the endogenous ABA content of the host plant. The ABA-deficient tomato mutants flacca and sitiens and their near-isogenic wild-type parental lines were used. Growth, stomatal conductance, shoot hormone concentration, competition assay for colonization of tomato root tips, and root expression of plant genes expected to be modulated by ABA and PGPR were examined.

Results: Contrary to the wild-type plants in which PGPR stimulated growth rates, PGPR caused growth inhibition in ABA-deficient mutant plants. PGPR also triggered an over accumulation of ethylene in ABA-deficient plants which correlated with a higher expression of the pathogenesis-related gene SI-PRIb.

Conclusions: Positive correlation between over-accumulation of ethylene and a higher expression of SI-PR1b in ABA-deficient mutant plants could indicate that maintenance of normal plant endogenous ABA content may be essential for the growth promoting action of B. megaterium by keeping low levels of ethylene production.
\end{abstract}

Keywords: Abscisic acid, Bacillus megaterium, Ethylene, Hormones, PGPR, Solanum lycopersicum, Rhizobacteria

\section{Background}

There are numerous reports of plant growth and yield stimulation by beneficial soil microorganisms [1-4]. A wide range of microorganisms which live in the soil are able to establish symbiotic and non-symbiotic associations with their host plants [5]. These microorganisms play important functions in the soil which include: (1) controlling the adverse effects of pathogens on plant growth, (2) alleviating negative effects of soil stresses on plant growth and yield production, (3) biofertilization, (4) enhancing root growth, and (5) rhizoremediation [6-9].

Plant growth-promoting rhizobacteria (PGPR) are among the most effective and best studied soil microorganisms which can promote plant performance. PGPR can be classified as extracellular bacteria (existing in the rhizosphere, on the root surface or in the spaces between cells) and intracellular bacteria (mainly $\mathrm{N}_{2}$ fixing bacteria) [5]. The

\footnotetext{
* Correspondence: rporcel@eez.csic.es

'Departamento de Microbiología del Suelo y Sistemas Simbióticos, Estación Experimental del Zaidín (EEZ-CSIC), Profesor Albareda 1, 18008 Granada, Spain

Full list of author information is available at the end of the article
}

action mechanisms of PGPR can be also divided into direct and indirect ones. Biofertilization, stimulation of root growth, rhizoremediation and plant stress control are the direct mechanisms. On the other hand, the mechanisms of biological control by which rhizobacteria can promote plant growth indirectly, by reducing the level of disease, include antibiosis, induction of systemic resistance and competition for nutrients and niches [8]. Hormones such as auxins, ethylene, gibberellins, (+)- abscisic acid (ABA) and cytokinins regulate plant growth and development $[10,11]$. Plant hormones are chemical messengers that affect the plant's ability to respond to its environment. They are organic compounds that are effective at very low concentration and are usually synthesized in one part of the plant and transported to another location. Each plant response is often the result of two or more hormones acting together. Because hormones stimulate or inhibit plant growth, they are also referred as plant growth regulators. Plant-growth-promoting bacteria that contain the enzyme 1-aminocyclopropane-1-carboxylate (ACC) deaminase facilitate plant growth and development by decreasing plant ethylene levels. ACC is the precursor for the production 
of ethylene, whose amounts are increased under stress, affecting adversely plant growth and yield production. Hence, ethylene is one of the hormones regulating plant growth under different conditions including stress [8]. Ethylene is a plant growth regulator essential for normal growth and development in plants. However, apart from this key function, ethylene also acts as a stress hormone when plants are exposed to salinity, drought, waterlogging, heavy metals or pathogens [12].

ABA plays an important role in many physiological processes in plants. This hormone is necessary for regulation of several events during late seed development and is crucial for the response to environmental stresses such as desiccation, salt and cold. Abscisic acid controls plant growth and inhibits root elongation [13], which means that there is a negative correlation between growth and the endogenous ABA content of plants [14]. Despite this, ABA-deficient plants are usually smaller than wild-type (wt) plants [15]. It has been reported that some bacterial species that interact with plants or live in the soil, synthesize ABA and other phytohormones such as indole-3-acetic acid (IAA), gibberellic acid, zeatin (cytokinin) and ethylene [16-18]. Some species from the genus Bacillus have been described not only as plant growth promoters but also as a biological control agents of diseases $[19,20]$. So far, although impacts of one specific PGPR on ABA relations of Pisum sativum have been studied [21], no studies have been conducted to explain how endogenous levels of ABA could affect the PGPR function of Bacillus. In our study, tomato was chosen as the host plant. Tomato has a number of wellknown ABA pathway mutants and represents an appropriate model for studying the role of endogenous ABA in plants responses to PGPR. The ABA-deficient tomato mutants flacca and sitiens and their near isogenic wild-type parental line were used in this study. Previous research has shown that these mutants have residual ABA levels (no more than $8 \%$ of the wild-type plants) [22] and are unable to increase their ABA levels when plants are exposed to stress [23].

A PGPR from degraded soil in southern Spain isolated by our group and identified as Bacillus megaterium [24] has been used in this study. Marulanda et al. [25] analyzed how this PGPR strain may influence two crucial components of plant salt tolerance such as root hydraulic characteristics and aquaporin regulation in maize plants. Maize plants inoculated with Bacillus megaterium subjected to salt stress, showed higher biomass production, lower necrotic leaf area and higher root hydraulic conductance than non inoculated control plants [25]. In previous studies carried out by the same group it has been showed that this Bacillus megaterium strain was able to increase drought resistance in plants growing under water-limited conditions [26] and to increase plant growth under nutrient deficiency conditions [24]. The aim of the present study was to determine whether the activity of Bacillus megaterium PGPR is affected by the endogenous abscisic acid (ABA) content of the host plant.

\section{Methods \\ Experimental design}

The experiment consisted of a randomized complete block design with two inoculation treatments: (1) non-inoculated control plants and (2) plants inoculated with the PGPR Bacillus megaterium strain which was isolated by MarulandaAguirre et al. [24], and two plant ABA line treatments: wild type and an ABA-deficient line (flacca or sitiens). There were ten replicated plants per treatment (one plant per pot). The plants were cultivated under well watered conditions throughout the entire experiment. Two different sets of experiments were carried out: one with wild type (cv Rheinlands Ruhm) and sitiens plants (from January to March) and the second with wild type (cv Ailsa Craig) and flacca plants (from March to May). All determinations (except biomass production that was measured in samples taken from both experiments) were carried out on samples taken from the second set of experiments.

\section{Soil and biological materials}

Peat and vermiculite mixture $(1: 1, \mathrm{v} / \mathrm{v})$ was sterilized $\left(120^{\circ} \mathrm{C}\right.$ for $20 \mathrm{~min}$ ). Seeds of tomato (Solanum lycopersicum) sitiens (LA0574) and its parental isogenic cv Rheinlands Ruhm, as well as flacca (LA3613) and corresponding parental isogenic cv Ailsa Craig, were obtained from the Tomato Genetics Resource Center (TGRC) at the University of California, Davis, CA, USA. The seeds were sterilized in a $70 \%$ ethanol solution for $2 \mathrm{~min}$, then $50 \%$ sodium hypochlorite solution for $8 \mathrm{~min}$ and finally washed several times with sterile water to remove any trace of chemicals that could interfere with seed germination. The seeds were placed on sterile vermiculite at $25^{\circ} \mathrm{C}$ to germinate and 10 d-old seedlings were transferred to plastic pots containing $500 \mathrm{~g}$ of the peat moss/vermiculite mixture (1:1, v/v). A suspension ( $0.5 \mathrm{~mL}$ per seed) of the bacterium Bacillus megaterium $\left(10^{9}\right.$ cell $\left.\mathrm{mL}^{-1}\right)$ grown in Luria-Bertani medium (LB) was sprinkled over each seedling one and seven days after planting. Non-inoculated control plants received the same number of applications with the same amount of growth medium without bacteria.

\section{Growth conditions}

Tomato plants were grown for two months in a greenhouse under controlled climatic conditions $\left(18-24^{\circ} \mathrm{C}\right.$, with an $18 \mathrm{~h} / 6 \mathrm{~h}$ light/dark period and 50-60\% relative humidity). A photoperiod of $16 \mathrm{~h}$ at a photosynthetic photon flux density (PPFD) of $600 \mu \mathrm{mol} \mathrm{m} \mathrm{m}^{-2} \mathrm{~s}^{-1}$, as measured with a light meter (model LI-188B; Licor Inc., Lincoln, NE, USA), was maintained throughout the experiment. Water was supplied daily to maintain constant soil 
water content close to water -holding capacity during the entire experiment.

\section{Biomass production}

At harvest (60 d after planting), the root system of 6 samples was separated from the shoot and fresh weight determined. Shoot and root dry weights were measured after drying in a forced draught oven at $70^{\circ} \mathrm{C}$ for $2 \mathrm{~d}$. Plant height was also determined.

\section{Stomatal conductance}

Stomatal conductance was recorded $2 \mathrm{~h}$ after dawn with the porometer system (Porometer AP4, Delta-T Devices Ltd., Cambridge, UK) in the last fully expanded leaf of six plants per treatment. Each measurement was repeated three times in each leaf, and the mean of the three measurements was considered in order to diminish variability in this parameter.

\section{Competition assay for colonization of tomato root tip}

In order to check the ability of the examined PGPR strain to colonize wild-type and mutant plants and to confirm its presence inside roots, a competition assay for colonization was carried out. The experiment consisted of a randomized complete block design with three plant ABA line treatment: wild type, sitiens and flacca plants and two inoculation treatments: (1) control plants inoculated with LB medium alone and (2) plants inoculated with Bacillus megaterium strain. Six replicates of each were done totaling 36. Sterilized tomato seeds were germinated in MS plates in darkness until plants had a root $1 \mathrm{~cm}$ in length. 10-days-old seedlings were transferred to glass bottles containing sterile peat and vermiculite mixture $(1: 1, \mathrm{v} / \mathrm{v})$. $1 \mathrm{~mL}$ seedling $^{-1}$ of LB medium (control plants) or a suspension (1 mL seedling ${ }^{-1}$ ) of Bacillus megaterium (inoculated plants) was sprinkled over each seed at the time of transferring to bottle. Bacillus megaterium was grown in LB medium supplemented with gentamycin $50 \mu \mathrm{g} \mathrm{mL}$ until $\mathrm{OD}_{600}=1.9-2$ that correspond to cell density of about $10^{9}$ cell $\mathrm{mL}^{-1}$. The glass bottles were kept for seven days in a controlled-climate growth chamber $\left(18-24^{\circ} \mathrm{C}, 50-60 \%\right.$ relative humidity, $16 \mathrm{~h}$ daylight) and the root systems reached an average length of $12 \mathrm{~cm}$. The bacterial growth inside the roots was determined as described by Marulanda et al. [26]. A $1 \mathrm{~cm}$-long distal root segment was cut, cleaned and surface-disinfected (20 min in 30\% [v:v] $\mathrm{H}_{2} \mathrm{O}_{2}$ followed by washing in five changes of distilled water). After grinding, $100 \mu \mathrm{L}$ aliquots were suspended in $10 \mathrm{~mL}$ of sterile water (dilutions $10^{-2}$ ) and $1 \mathrm{~mL}$ of this suspension was serially diluted to each dilution of $10^{-2}-10^{-7}$. Dilutions were plated in agar nutrient broth medium $\left(8 \mathrm{~g} \mathrm{~L}^{-1}\right)$ supplemented with gentamycin $50 \mu \mathrm{g} \mathrm{mL}^{-1}$ and cultivated for $48 \mathrm{~h}$ at $28^{\circ} \mathrm{C}$. Colonization experiment was repeated twice.

\section{Analysis of endogenous $A B A$}

The concentration of ABA was analyzed in shoot extracts using high performance liquid chromatographyelectrospray-mass spectrometry (HPLC-ESI-MS/MS). The extraction and purification of ABA were carried out using the method described by Bacaicoa et al. [27] with some variations. Frozen $0.5 \mathrm{~g}$ sample of plant tissue (previously ground to a powder in a mortar with liquid $\mathrm{N}$ ) was homogenized with $5 \mathrm{~mL}$ of precooled $\left(-20^{\circ} \mathrm{C}\right)$ methanol: water $(80: 20, \mathrm{v} / \mathrm{v})$ and $2.5 \mathrm{mM}$ Na diethyldithiocarbamate (DDTC). The deuterium-labelled internal standard $\left[{ }^{2} \mathrm{H}_{6}\right]$ (+)-cis, trans-abscisic acid, (from Olchemim, Olomouc, Czech Republic) was added (100 $\mu \mathrm{L}$ of a stock solution of $400 \mathrm{ng} \mathrm{mL}^{-1}$ of standard in methanol) to the extraction medium. After overnight extraction at $-20^{\circ} \mathrm{C}$, solids were separated by centrifugation at $12000 \times \mathrm{g}$ for $10 \mathrm{~min}$ at $4^{\circ} \mathrm{C}$ using a Centrikon T-124 centrifuge with an A8.24 rotor (Kontron Instruments, Cumbernauld, United Kingdom) and re-extracted for $1 \mathrm{~h}$ with an additional $4 \mathrm{~mL}$ of extraction mixture. Supernatants were passed through a Strata C18-E cartridge $(3 \mathrm{~cm} 3,200 \mathrm{mg})$ (Phenomenex, Torrance, CA; Ref. 8B-S001-FBJ), preconditioned with $4 \mathrm{~mL}$ of methanol followed by $2 \mathrm{~mL}$ of extraction medium. After evaporation at $40^{\circ} \mathrm{C}$ of aqueous phase using a Labconco Vortex Evaporator (Labconco Co., Kansas City, MO), $0.5 \mathrm{~mL}$ of $1 \mathrm{M}$ formic acid was added. Then, ABA was extracted with two portions of 5 and $4 \mathrm{~mL}$ of diethyl ether, and the organic phase was evaporated to dryness. The residue was redissolved in $250 \mu \mathrm{L}$ of methanol: $0.5 \%$ acetic acid $(40: 60, v / v)$. Before the injection in the HPLC-ESIMS/MS system, the solution was centrifuged at $8000 \times \mathrm{g}$ for $5 \mathrm{~min}$.

ABA was quantified by HPLC-ESI-MS/MS using a HPLC device (2795 Alliance HT; Waters Co., Milford, MA) coupled to a 3200 Q TRAP LC/MS/MS System (Applied Biosystems/MDS Sciex, Ontario, Canada), equipped with an electrospray interface. A reverse-phase column (Synergi $4 \mu \mathrm{m}$ Hydro-RP 80A, $150 \times 2 \mathrm{~mm}$; Phenomenex, Torrance, CA) was used. A linear gradient of methanol (A) and $0.5 \%$ acetic acid in water (B) was used: $35 \% \mathrm{~A}$ for $1 \mathrm{~min}, 35 \%$ to $95 \% \mathrm{~A}$ in $9 \mathrm{~min}, 95 \% \mathrm{~A}$ for $4 \mathrm{~min}$ and $95 \%$ to $35 \% \mathrm{~A}$ in $1 \mathrm{~min}$, followed by a stabilization time of $5 \mathrm{~min}$. The flow rate was $0.20 \mathrm{~mL} \mathrm{~min}^{-1}$, the injection volume was $40 \mu \mathrm{L}$ and column and sample temperatures was $20^{\circ} \mathrm{C}$. The detection and quantification of ABA was carried out using multiple reaction monitoring (MRM) in the negative-ion mode, employing multilevel calibration curves with deuterated hormone as an internal standard. For further details see Bacaicoa et al. [27].

\section{Analysis of endogenous ACC content}

The extraction and purification of ACC (1-aminocyclopropane-1-carboxylic acid) was carried out using the method described by Mora et al. [28]. Frozen plant 
tissue $(0.25 \mathrm{~g})$ previously ground using mortar and pestle with liquid nitrogen was homogenized with $20 \mu \mathrm{L}$ of $\mathrm{d}_{4} \mathrm{ACC}(3 \mu \mathrm{g} / \mathrm{mL}$ in acetonitrile/ acetic acid $0.2 \%(90 /$ $10)$ ) and $3 \mathrm{~mL}$ of $\mathrm{MeOH} / \mathrm{H}_{2} \mathrm{O} / \mathrm{HCOOH}(15 / 4 / 1, \mathrm{v} / \mathrm{v} / \mathrm{v})$ at $-20^{\circ} \mathrm{C}$. The mixture was vortexed $(2000 \mathrm{rpm})$ for $10 \mathrm{~min}$. After overnight extraction at $-20^{\circ} \mathrm{C}$, solids were separated by centrifugation $\left(12000 \mathrm{rpm}, 10 \mathrm{~min}, 4^{\circ} \mathrm{C}\right)$. Supernatants were purified using a Strata C18-E cartridge (Ref 8B-S001-FBJ, Phenomenex, Torrance, CA, USA) preconditioned with $4 \mathrm{~mL}$ of methanol and $2 \mathrm{~mL}$ of $\mathrm{MeOH} /$ $\mathrm{H}_{2} \mathrm{O} / \mathrm{HCOOH}(15 / 4 / 1, \mathrm{v} / \mathrm{v} / \mathrm{v})$. The eluent was evaporated at $40^{\circ} \mathrm{C}$ until methanol was removed (Vortex evaporator mod. 432-2100 from Labconco Corporation, Kansas City, MO, USA). The residue was re-dissolved with $2 \mathrm{~mL}$ of $\mathrm{MeOH} / \mathrm{H}_{2} \mathrm{O} / \mathrm{HCOOH}(15 / 4 / 1)$ and stored at $-20^{\circ} \mathrm{C}$. After $1 \mathrm{~h}$, the extract was newly centrifuged $(12000 \mathrm{rpm}$, $10 \mathrm{~min}, 4^{\circ} \mathrm{C}$ ). Supernatants were purified using the same Strata C18-E cartridge. After evaporation to near dryness, the residue was re-dissolved in $2 \mathrm{~mL}$ of formic acid $1 \mathrm{M}$, and applied to an Oasis MCK column (Ref. 186000254, Waters Co., Milford, MA) preconditioned with $4 \mathrm{~mL}$ of methanol and $2 \mathrm{~mL}$ of formic acid $1 \mathrm{M}$. The column was washed successively with $1 \mathrm{~mL}$ of formic acid $1 \mathrm{M}$ and $1 \mathrm{~mL}$ of methanol. ACC was eluted with $1 \mathrm{~mL}$ of $0.35 \mathrm{M}$ $\mathrm{NH}_{4} \mathrm{OH}$. This eluted fraction was evaporated to dryness in the vortex evaporator and re-dissolved in $500 \mu \mathrm{L}$ of acetonitrile/acetic acid $0.2 \%$ (90:10). Finally the eluted fraction was centrifuged (10000 rpm, $8 \mathrm{~min}$ ) and injected in the LC/MS/MS systems.

ACC was quantified by HPLC linked to a 3200 QTRAP LC/MS/MS system (Applied Biosystems/ MDS Sciex, Ontario, Canada), equipped with a turbo ion spray interface. Detection and quantification were performed by multiplereaction-monitoring (MRM) in the positive-ion mode, employing a multilevel calibration graph with deuterated $\mathrm{d}_{4} \mathrm{ACC}$ as internal standards. For further details see Mora et al. [28].

\section{Analysis of ethylene production in plant tissues}

Intact plants were enclosed in sealed acetate cylinders which were incubated at room temperature for $24 \mathrm{~h}$. Samples of $500 \mu \mathrm{L}$ were withdrawn from each acetate cylinder with a syringe and the ethylene content was quantified with a Hewlett Packard model 5890 gas chromatograph equipped with a Poropak- $\mathrm{R}$ column and a hydrogen flame ionization detector as described Porcel et al. [29].

\section{RNA isolation and synthesis of first strand CDNA}

Total RNA was isolated from tomato leaves from 3 different plants of each treatment by phenol/chloroform extraction method [30]. DNase treatment of total RNA and cDNA synthesis was performed according to
Qiagen's protocol (Quantitect Reverse Transcription KIT Cat\#205311, Qiagen, CA).

\section{Quantitative real-time RT-PCR}

The expression of Solanum lycopersicum 1-Amynocyclopropane-1-carboxylic acid oxidase (Sl-ACO4), 1Aminocyclopropane-1-caboxylic acid synthase (Sl-ACS7), pathogenesis-related 1b (Sl-PR1b), 9-cis-epoxycarotenoid dioxygenase (Sl-NCED), and SlLE16 genes was studied by real-time PCR by using iCycler (Bio-Rad, Hercules, California, USA).

The primer sets used to amplify each analyzed gene in the synthesized cDNAs are shown in Table 1.

Each $23 \mu \mathrm{L}$ reaction contained $3 \mu \mathrm{L}$ of a dilution 1:10 of the cDNA, $10.5 \mu \mathrm{L}$ of Master Mix (Bio-Rad Laboratories S.A, Madrid), $8.6 \mu \mathrm{L}$ of deionised water and $0.45 \mu \times \mathrm{L}$ of each primer pair. The PCR program consisted in $3 \mathrm{~min}$ incubation at $95^{\circ} \mathrm{C}$ to activate the hotstart recombinant Taq DNA polymerase, followed by 32 cycles of $30 \mathrm{~s}$ at $95^{\circ} \mathrm{C}, 30 \mathrm{~s}$ at $58^{\circ} \mathrm{C}$ and $30 \mathrm{~s}$ at $72^{\circ} \mathrm{C}$, where the fluorescence signal was measured. The specificity of the PCR amplification procedure was checked with a heat dissociation protocol (from $70-100^{\circ} \mathrm{C}$ ) after the final cycle of the PCR.

Four independent biological replicates were used and each real-time PCR reaction was done in triplicate. These values were then normalized using the threshold cycle $\left(C_{\mathrm{T}}\right)$ value for the tomato household gene Sl-actin. The relative levels of transcription were calculated by using the $2^{-\Delta \mathrm{Ct}}$ Method [31]. Negative controls without cDNA were used in all PCR reactions.

\section{Statistical analysis}

The data were processed by the two-way analysis of variance (ANOVA) with PGPR inoculation and plant genotype

\section{Table 1 Primers used in this study}

\begin{tabular}{|c|c|c|}
\hline Primer & Sequence & $\begin{array}{c}\text { Annealing } \\
\text { Temperature }\left({ }^{\circ} \mathrm{C}\right)\end{array}$ \\
\hline SIActin For & $5^{\prime}$ - TCACCACCACTGCTGAACGGGA-3' & 58 \\
\hline SIActin Rev & 5' - TGGGCAACGGAACCTCTCAGC -3' & \\
\hline SIPR1b For & 5' - GGGAGGGCAGCCGTGCAATT -3' & 58 \\
\hline SIPR1b Rev & $5^{\prime}$ - TGCAACGTGCCCGACCACAA -3' & \\
\hline SIACO4 For & 5' - TTCGCGCTCACACGGATGCT -3' & 58 \\
\hline SIACO4 Rev & $5^{\prime}$ - CACCTCTAGCTGATCGCCGAGG -3' & \\
\hline SIACS7 For & 5' - CGGTCTCCCCGGTTITCGCA -3' & 58 \\
\hline SIACS7 Rev & 5' - GTGGCCGCGGAGACAACCAT -3' & \\
\hline SINCED For & $5^{\prime}$ - ACAGCCGACCCACGAGTCCA -3' & 58 \\
\hline SINCED Rev & 5' - GGTGTCCGGCGGTTGGTTCA -3' & \\
\hline SILE16 For & 5' - TCCCTTATCTCGAGGGTCGC -3' & 58 \\
\hline SILE16 Rev & 5' - CGCTGTCTTCCGGTCTTCTG -3' & \\
\hline
\end{tabular}


as sources of variation, using the SPSS 12.0 statistical software package, (SPSS Inc., Chicago, IL, USA). The means were considered to be significantly different at $\mathrm{P}<0.05$ after the LSD test. The gene expression data were analyzed using Student's unpaired $t$ test $(\mathrm{P}<0.05)$ in order to compare inoculated plants with their respective non-inoculated controls. To analyze the results of competition assay for colonization of tomato root tip, the data were subjected to the Duncan's honestly significant difference test.

\section{Results}

\section{Biomass production}

Shoot and root dry weight of both flacca and sitiens mutant plants followed the same pattern after inoculation with $B$. megaterium and when compared to wild-type (wt) plants. Shoot dry weight was higher in inoculated wt plants than in the corresponding non-inoculated ones (11\% cv Ailsa Craig and 20\% cv Rheinlands Ruhm). However, in mutant plants shoot dry weight decreased due to inoculation (30\% flacca plants and 20\% sitiens plants). Significant differences for shoot dry weight were found among wt and mutant plants (flacca and sitiens) regardless of microbial treatment (Figures 1A, 2A). Root dry weight was much higher in wt plants (inoculated and noninoculated) than ABA-deficient mutant plants. No significant differences in root dry weight were observed as a consequence of inoculation with the PGPR in any plant line (both wt, flacca and sitiens); (Figures 1B, 2B).

Finally, total plant dry weight was higher in inoculated wt plants than in the corresponding non-inoculated ones (13\% cv Ailsa Craig and 20\% cv Rheinlands Ruhm). In contrast, in mutant plants the opposite effect was observed. Inoculation had a negative effect on total dry weight both in flacca and sitiens plants (Figures 1C, 2C).

Plant height was similar in all treatments. In the second experiment carried out with wild-type cv Ailsa Craig and flacca plants, only inoculated flacca plants showed a significant decrease in height compared with wild-type plants but not with non-inoculated flacca plants (Figure 1D). In the first experiment in which sitiens plants and their parental isogenic wild-type cv Rheinlands Ruhm were grown in other season, significant differences were observed. While in wild-type plants there was no significant change by inoculation, in sitiens plants a significant decrease was showed by effect of inoculation with Bacillus megaterium (Figure 2D). Thus, while inoculation with B. megaterium increased biomass in wt plants, in sitiens and in flacca plants the opposite happened.

ANOVA showed highly significant $(\mathrm{P}<0.001)$ effects of genotype on shoot, root, total dry weight and height, and significant $(\mathrm{P}<0.05)$ effects of genotype $\times \mathrm{PGPR}$ interaction on shoot and total dry weight both in flacca and sitiens plants (Table 2).

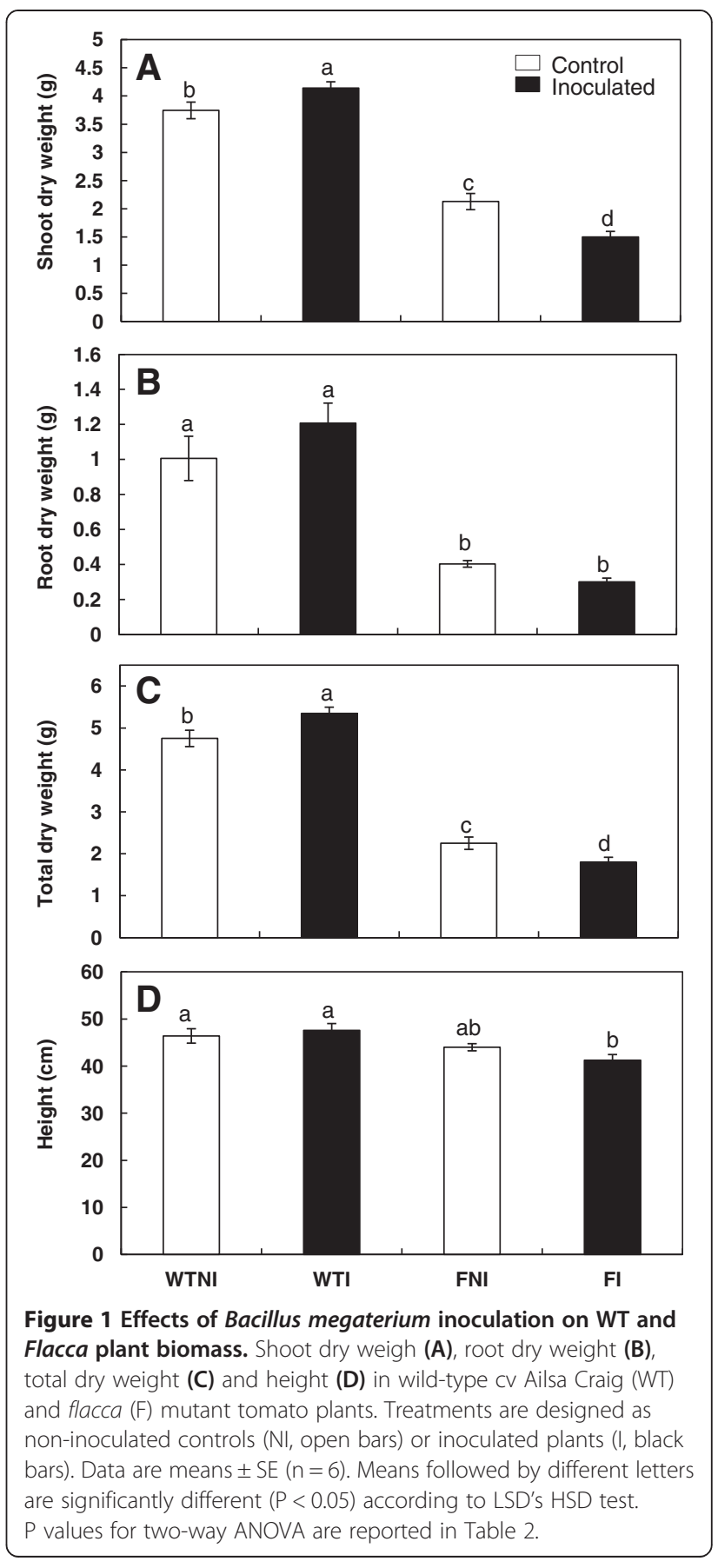

\section{Stomatal conductance}

Stomatal conductance was not affected by PGPR addition. However, flacca and sitiens mutant plants showed a much higher stomatal conductance than wt plants (Figure 3A, $3 \mathrm{~B})$. ANOVA analysis showed highly significant $(\mathrm{P}<0.001)$ effects of genotype but not of inoculation (Table 2).

\section{Competition assay for colonization of tomato root tip}

We carried out a competition assay for colonization in order to check the presence of Bacillus megaterium and 


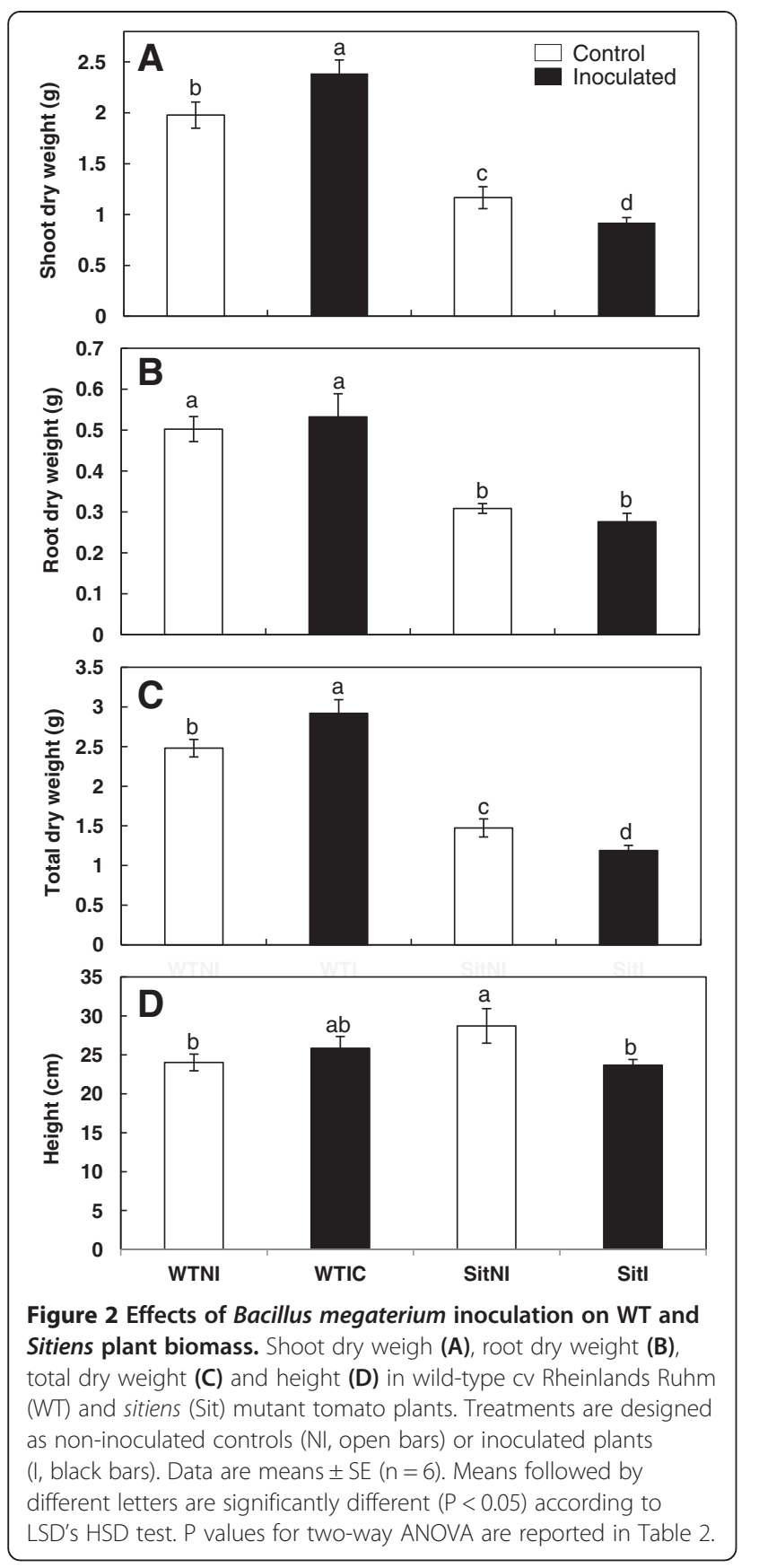

its ability to colonize root wild-type and ABA-deficient mutant plants. As expected, in control non-inoculated plants we confirmed that there was no presence of Bacillus in roots. However, in inoculated plants, although it was present in all plants (wild-type, sitiens and flacca), the presence of $B$. megaterium was significantly lower in sitiens plants. Root sitiens plants showed 3.0, wt showed 7.4 and flacca plants $9.5 \mathrm{cfu} 10^{6} \mathrm{~cm}^{1}$ root. Due to the similarity of results concerning biomass production and stomatal conductance, and the lower colonization of $B$. megaterium in sitiens plants, from now on, the following
Table 2 Two-way analysis of variance (ANOVA)

\begin{tabular}{|c|c|c|c|}
\hline \multirow[b]{2}{*}{ WT/Flacca } & \multicolumn{3}{|c|}{ Significance of sources of vatiation } \\
\hline & PGPR (P) & Genotype (G) & PxG \\
\hline \multicolumn{4}{|l|}{ Parameter measured } \\
\hline Total DW & ns & $* * *$ & $* *$ \\
\hline Shoot DW & ns & $* * *$ & ** \\
\hline Root DW & ns & $* * *$ & ns \\
\hline Height & ns & $* * *$ & ns \\
\hline Stomatal conductance & ns & $* * *$ & ns \\
\hline $\mathrm{ABA}$ & ns & $* * *$ & ns \\
\hline ACC & ns & $* * *$ & ** \\
\hline Ethylene & $* * *$ & ns & ns \\
\hline SI-PRIb & ** & $* * *$ & *** \\
\hline SI-ACO4 & * & ns & ns \\
\hline SI-ACS7 & ** & $* * *$ & *** \\
\hline SI-NCED & ns & $* * *$ & $* * *$ \\
\hline WT/Sitiens & PGPR (P) & Genotype (G) & $P \times G$ \\
\hline \multicolumn{4}{|l|}{ Parameter measured } \\
\hline Total DW & ns & $* * *$ & $*$ \\
\hline Shoot DW & ns & $* * *$ & $*$ \\
\hline Root DW & ns & $* * *$ & ns \\
\hline Height & ns & $* * *$ & ns \\
\hline Stomatal conductance & ns & $* * *$ & ns \\
\hline
\end{tabular}

Significance of the sources of variation are PGPR (P), Genotype (G) and PGPR $x$ Genotype (PxG).

${ }^{*} \mathrm{P} \leq 0.05 ;{ }^{* * P} \leq 0.01 ;{ }^{* * *} \mathrm{P} \leq 0.001 ; \mathrm{ns}$, not significant.

determinations were done only in flacca plants, where the decrease of biomass by inoculation was more pronounced.

\section{$A B A$ and $A C C$ concentration and production rate of ethylene}

Since we studied whether the activity of Bacillus megaterium PGPR was affected by the endogenous ABA concentration of the host plant, we analyzed ABA and ACC concentration and ethylene production rate in leaves.

Endogenous ABA concentration in leaves was lower in mutant plants than in wt plants. However, in ABAdeficient mutants, ABA decreased by $24 \%$ as a consequence of PGPR presence (Figure 4A). ANOVA showed highly significant $(\mathrm{P}<0.001)$ effects of genotype (Table 2$)$.

In leaves of wt plants, ACC concentration increased by 90\% as a result of inoculation with Bacillus megaterium, while in leaves of mutant plants there were no significant differences as a consequence of inoculation. However, leaves of flacca plants showed higher intrinsic ACC concentration than wt plants (Figure 4B). ANOVA showed highly significant $(P<0.01)$ effects of both genotype and genotype $\times$ PGPR interaction on ACC concentration in tomato leaves (Table 2). 

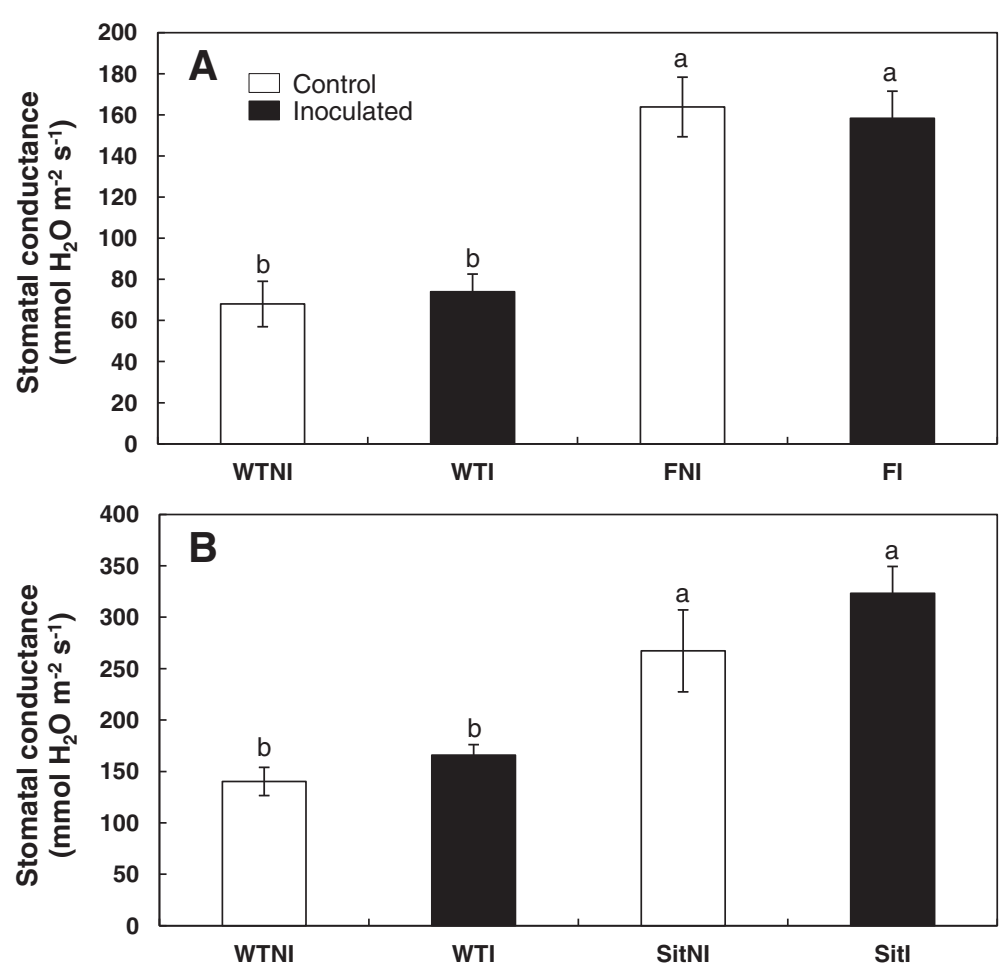

Figure 3 Effects of Bacillus megaterium inoculation on stomatal conductance. Wild-type cv Ailsa Craig (WT) vs. flacca (F) (A) and wild-type cv Rheinlands Ruhm (WT) vs sitiens (Sit) (B) mutant tomato plants were analyzed. Treatments are designed as non-inoculated controls ( $\mathrm{NI}$, open bars) or inoculated plants (I, black bars). Data are means $\pm S E(n=6)$. Means followed by different letters are significantly different $(P<0.05)$ according to LSD's HSD test. P values for two-way ANOVA are reported in Table 2.

Ethylene production rate was increased nearly 300\% in leaves of flacca mutants when inoculated with the PGPR. PGPR inoculation did not change significantly the ethylene production rate of wt leaves. There were no significant differences in ethylene production between non-inoculated leaves of both plant lines (Figure 4C). ANOVA also showed highly significant $(\mathrm{P}<0.001)$ effects of PGPR inoculation on ethylene production rate (Table 2 ).

\section{Quantitative real-time RT-PCR}

The expression of Sl-PR1b, Sl-ACO4, Sl-ACS7, Sl-NCED and $S l-L E 16$ genes was analyzed in leaves of each plant treatment (wt and flacca plants). Sl-PR1b and Sl-ACS7 gene expression increased in leaves of ABA-deficient mutant plants in the presence of the PGPR, while in wt leaves their expression went down (Figure 5). Sl-NCED gene expression was shown to be inhibited in ABAdeficient mutant plants inoculated with PGPR compared with non-inoculated plants, while an important induction of gene expression was observed in inoculated wt plants compared with uninoculated wt plants (Figure 5). The data on Sl-NCED gene expression obtained for flacca mutant plants corroborated ABA-deficient phenotype in these plants since both inoculated and non-inoculated mutant plants showed a lower relative gene expression than wt ones (Figure 5). In wild-type plants Sl-LE16 gene expression increased by inoculation but in flacca plants no gene expression was observed. Thus, the expression response of Sl-PR1b, Sl-ACS7 and Sl-NCED genes to PGPR inoculation was the opposite in wt and flacca leaves.

ANOVA showed very significant effects $(\mathrm{P}<0.001)$ of both genotype and genotype $\times$ PGPR interaction on $\mathrm{Sl}$ $P R 1 b, S l-A C S 7$ and Sl-NCED gene expression (Table 2).

\section{Discussion}

Plant growth-promoting rhizobacteria are found in soil and when they are in association with the plant roots can stimulate the growth of the host [32]. One of the mechanisms involved in this effect is the production or degradation of hormones that regulate plant growth and development. It is known that PGPR affect root hormone concentration, and can also alter root-to-shoot longdistance signalling to mediate shoot hormonal status [33]. Several rhizobacteria produce ABA in culture media or regulate plant ABA status [17]. In fact, although the biochemical mechanisms by which $\mathrm{ABA}$ is produced in planta have been well characterized [33], there are no studies concerning the role of endogenous plant ABA on PGPR activity. Herrera-Medina et al. [34] by comparative analysis of two ABA-deficient tomato mutant plants 

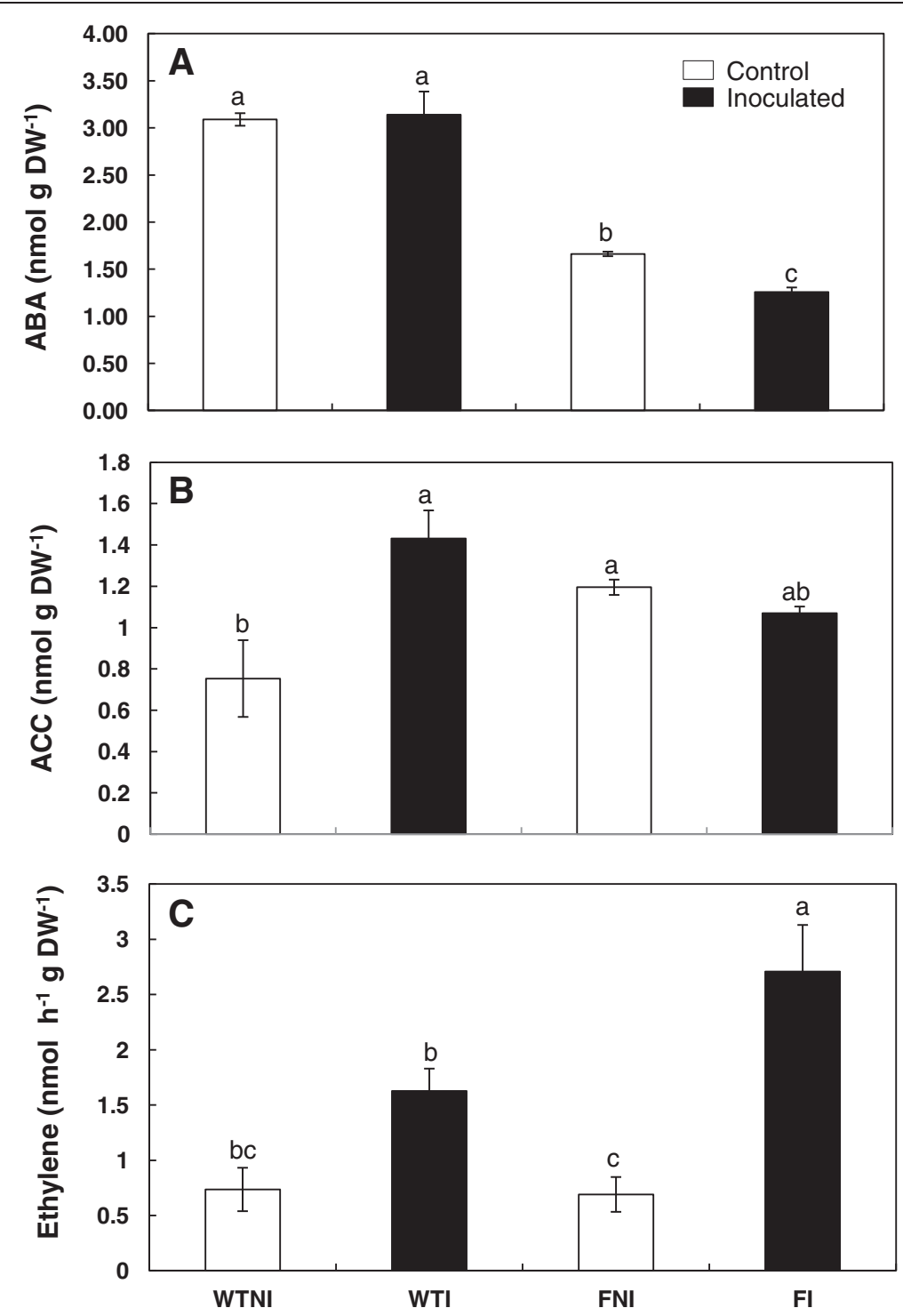

Figure 4 Effects of Bacillus megaterium inoculation on hormones. Concentration of shoot ABA (A) and ACC (B) and production rate of ethylene (C) in wild-type cv Ailsa Craig (WT) and flacca (F) mutant tomato plants were determined. Treatments are designed as non-inoculated controls (NI, open bars) or inoculated plants (I, black bars). Data are means $\pm S E(n=6)$. Means followed by different letters are significantly different $(P<0.05)$ according to LSD's HSD test. $P$ values for two-way ANOVA are reported in Table 2.

showed that there were both quantitative and qualitative differences in the pattern of arbuscular mycorrhization colonization. ABA deficiency induced ethylene production, suggesting that one of the mechanisms used by ABA to determine susceptibility to fungal infection is through negative modulation of the ethylene pathway.

In this study, we used ABA-deficient tomato mutants (flacca and sitiens) together with their near-isogenic wt parent to study how endogenous ABA can interfere with PGPR function. Sitiens and flacca are blocked in the final step of the ABA biosynthetic pathway, where the enzyme AAO catalyses the oxidation of abscisic aldehyde to ABA $[35,36]$. Sitiens is known to have a mutation in the AAO enzyme and mutant leaves contain only c. $11 \%$ of the wild-type ABA levels [35,37]. The mutant flacca has a mutation in a MoCo cofactor required for the activity of AAO and mutant leaves contain c. $33 \%$ of the wild-type ABA levels $[37,38]$. The poor growth and strong leaf epinasty shown in the tomato mutants notabilis, as well as flacca and sitiens has been shown to occur even under non-wilting conditions and has been attributed, at least partially, to an excess of ethylene [39]. However, our results have shown that there are no significant differences in ethylene production rate between ABA-deficient mutant and its near-isogenic wt parental. Marulanda et al. [26] showed that the same Bacillus megaterium strain that 
wild-type
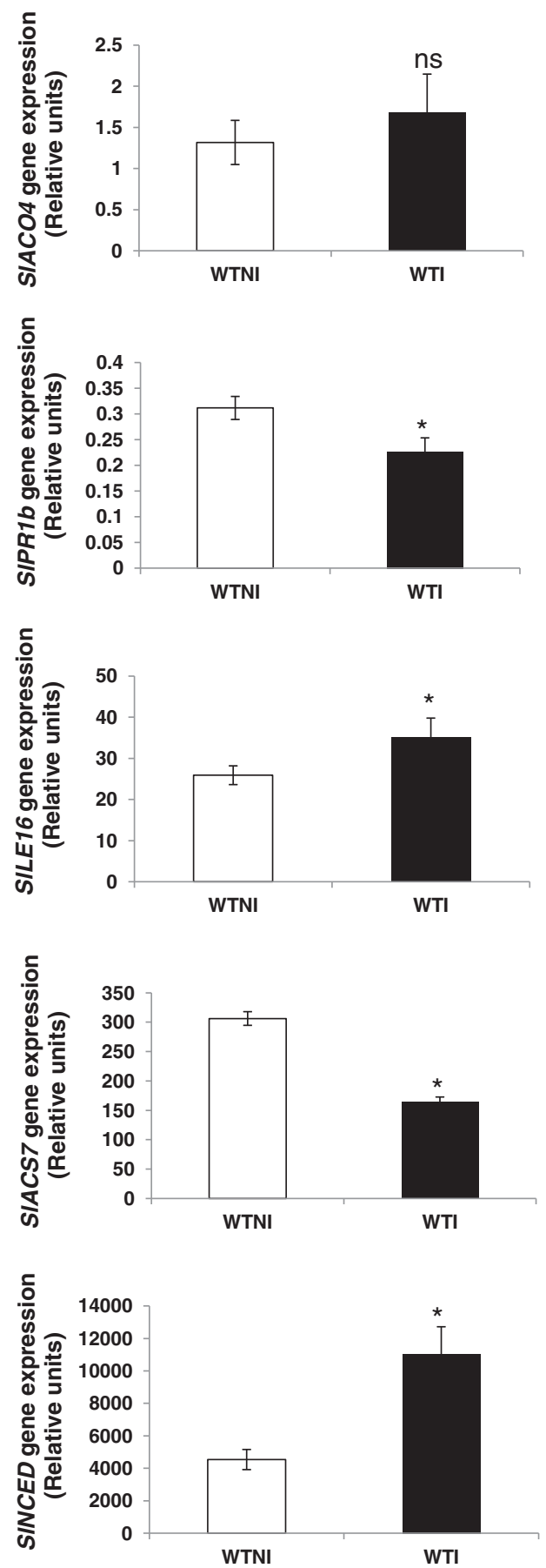

flacca mutant
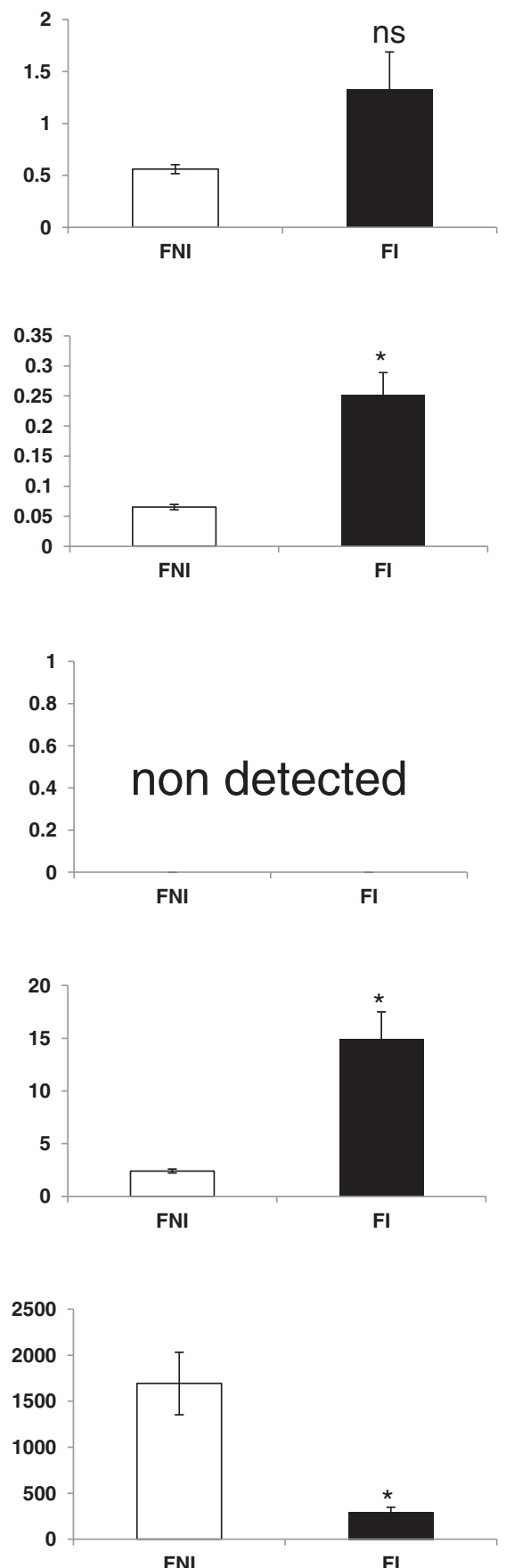

Figure 5 Effects of Bacillus megaterium inoculation on gene expression. Analysis of SI-PR16, SI-ACO4, SI-ACS7, SI-NCED and SI-LE16 gene expression by real time quantitative RT-PCR in leaves of wild-type cv Ailsa Craig tomato plants and mutant flacca inoculated with Bacillus megaterium. Treatments are designed as non-inoculated plants (white bars) or inoculated wild-type or flacca plants (black bars). Data represent the mean values \pm SE of four independent biological replicates. Means followed by asterisk are significantly different with respect to corresponding non-inoculated control $(P<0.05)$ as determined by t-student test. $\mathrm{P}$ values for two-way ANOVA are reported in Table 2. 
was used here, had a positive effect on Trifolium repens growth. In the present study, this positive effect was observed in wt plants but not in flacca or sitiens ones. ABAdeficient plants showed a significant decrease in biomass production as previously demonstrated [40], indicating that endogenous ABA probably has an important role in keeping plant growth. In the same way, inoculated flacca and sitiens mutant plants showed lower heights than inoculated wt plants. Therefore, the low levels of ABA in these mutant plants switched the effect of the B. megaterium strain used here from plant growth promoting rhizobacteria to plant growth inhibiting rhizobacteria.

Although B. megaterium was present in all plants (wildtype, sitiens and flacca), the presence of this PGPR was significantly lower in sitiens plants. It is possible that the lower ABA may be inhibiting the root colonization. Therefore, a minimal content of ABA should be required for $B$. megaterium colonization. Similar results were found for arbuscular mycorrhizal symbiosis [34].

It has been proposed that restriction of ethylene production may be a widespread function of ABA. In fact, it is well known that ethylene and $\mathrm{ABA}$ act antagonistically to modulate development [41], shoot growth [39] and disease resistance in plants [42]. In addition, there is some evidence that ABA and ethylene antagonistic interaction could interfere with arbuscular mycorrhizal formation [43]. Thus, it appears that the B. megaterium strain used in this study may increase ethylene production of the host plant. Since flacca plants have lower amounts of ABA, the production of ethylene by the PGPR inoculation was exacerbated and even a reduction of the ABA levels took place.

There is a negative correlation between growth and the endogenous ABA concentration of plants [14] but not under stress conditions [44]. As we expected, ABAdeficient mutant plants showed much lower ABA concentration than wt plants, however inoculation with PGPR in these plants decreased considerably the ABA concentration in leaves, correlating with the decrease in the expression of the ABA-biosynthesis gene Sl-NCED. We observed a direct correlation between growth and the endogenous ABA content in flacca mutant plants. The hormonal response of flacca plants to the PGPR inoculation resembles the plant response to a pathogen, a dramatic increase in ethylene contents [45].

The $P R 1 b$ gene is considered an indicator of plant responses to pathogens [46]. Induction of plant systemic acquired resistance (SAR) correlates with the expression of pathogenesis-related (PR) genes [47-49]. Among PR genes, PR1 expression is a paradigm for the coregulation of PR genes during SAR [50]. The interactions between $\mathrm{ABA}$ and ethylene in responses to plant pathogens are poorly understood. Whereas several reports have shown an inverse correlation between ABA levels and resistance

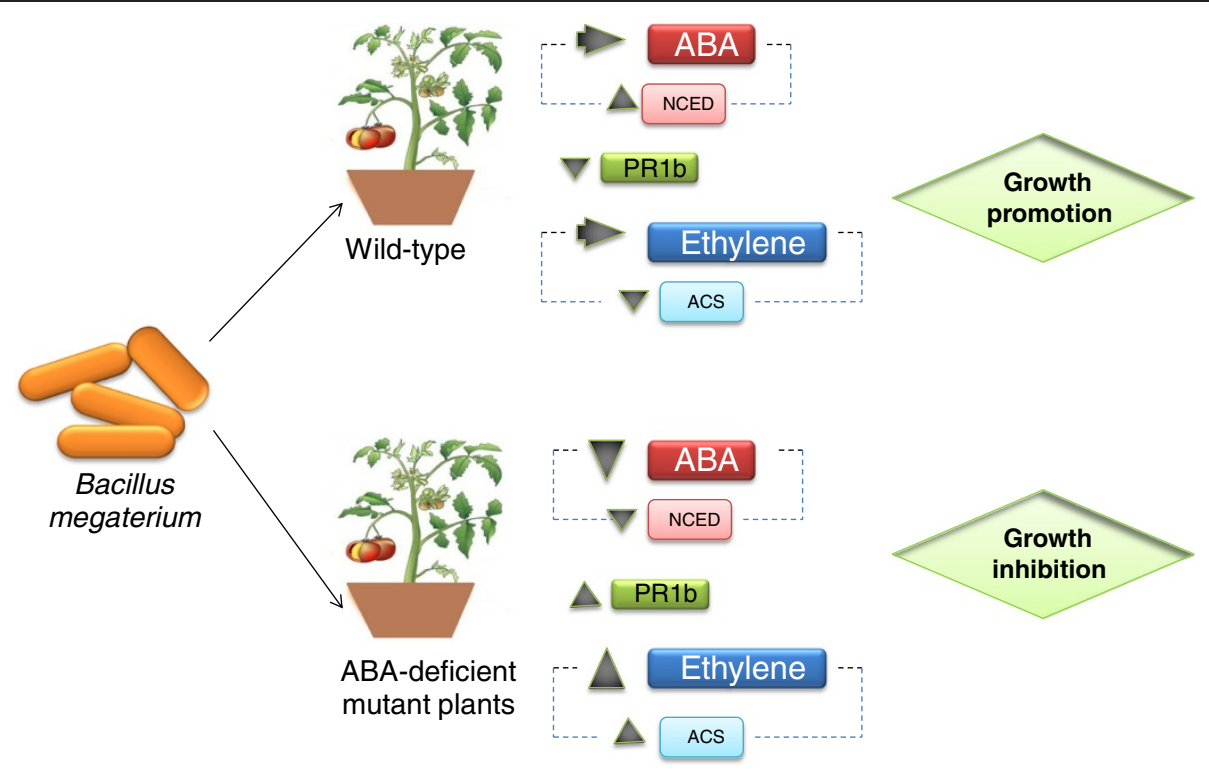

Figure 6 Schematical figure showing results in wild-type and ABA-deficient mutant plants when are inoculated with Bacillus megaterium. In wild-type plants, ABA concentration as well as ethylene didn't show significant differences (compared to the non-inoculated ones). However, ABA biosynthesis-related enzyme NCED gene expression increased and ethylene biosynthesis-related enzyme ACS gene expression, decreased. In ABA-deficient mutant plants, ABA concentration as well as the enzyme involved in ABA biosynthesis gene expression, decreased. On the contrary, both ethylene and ACS gene expression increased with respect to non inoculated plants. SI-PR1b gene expression was opposite in both kinds of plants. While in wild-type SI-PR1b gene expression decreased, in ABA-deficient mutant plants increased significatively. In conclusion, wild-type plants inoculated with Bacillus megaterium showed a growth promotion while inoculated ABA-deficient mutant plants showed an inhibition of growth. 
to pathogens with different lifestyles in several plant species, others have suggested a positive role of this hormone in activation of defence gene expression and pathogen resistance [51]. In ABA-deficient tomato and maize ABAbiosynthesis mutants, exogenous ABA application suppresses ethylene production [41,52,53]. Consistent with this, Anderson et al. [42] found an antagonistic interaction between ethylene and ABA signalling mutants in vegetative tissues. Here, we found that in flacca plants with lower levels of ABA a dramatic increase in ethylene occurs with a concomitant increase in the expression of the pathogenesis-related gene Sl-PR1b. The results of this study are in line with the recent studies suggesting that beneficial microbes can also act as pathogens. This has been reported not only for microbes that induce systemic acquired resistance (SAR), but also for induced systemic resistance (ISR) inducers (see [54,55]). Since several studies have shown that there is a strong antagonism between ABA and salicylic acid (SA) signalling [56,57], other alternative explanation for PGPR reduction of growth in flacca plants could be that the ABA-deficient mutants could recognize Bacillus by a possible microbe-associated molecular pattern (MAMP) and could trigger a strong SAdependent defence, leading to growth retardation.

In wt plants a significant increase in ACC concentration was observed after inoculation with PGPR, while no significant differences were observed in flacca mutant plants as a result of inoculation, most probably because almost all the ACC molecules were converted to ethylene in flacca plants. In fact, only ABA-deficient mutant plants showed a significant increase (6 times) of SlACS7, encoding for an enzyme involved in the ethylene synthesis [58] when they were inoculated with PGPR.

\section{Conclusions}

In wild-type plants, $\mathrm{ABA}$ and ethylene content didn't show significant differences compared to the noninoculated plants. However, the expression of $\mathrm{ABA}$ biosynthesis-related enzyme NCED gene increased and ethylene biosynthesis-related enzyme ACS gene expression decreased. In ABA-deficient mutant plants, $A B A$ concentration as well as the enzyme involved in ABA biosynthesis gene expression decreased. On the contrary, both ethylene and ACS gene expression increased with respect to non inoculated plants. Sl-PR1b gene expression was opposite in both kinds of plants. While in wild-type Sl-PR1b gene expression decreased, in ABA-deficient mutant plants significantly increased. In conclusion, Bacillus megaterium stimulated growth in wild type plants, but inhibited growth in ABA-deficient mutant plants (Figure 6).

Positive correlation between over accumulation of ethylene and a higher expression of Sl-PR1b in ABA-deficient mutant plants could indicate that plant endogenous ABA may be essential for the growth-promoting effect of PGPR by maintaining low ethylene production levels.

\section{Competing interests}

The authors declare that they have no competing interests.

\section{Authors' contributions}

RP carried out the physiological and gene expression studies. RP also performed the statistical analyses and drafted the manuscript. AMZ and JMGM carried out hormone content analyses. RA and RP conceived the study and RA moreover helped to draft the manuscript. All authors read and approved the manuscript.

\section{Acknowledgements}

This work was supported by the Spanish Ministry of Economy and Competitiveness Project AGL2011-25403. We thank to Janusz J Zwiazek (University of Alberta, Canada) for revising the final text.

\section{Author details}

'Departamento de Microbiología del Suelo y Sistemas Simbióticos, Estación Experimental del Zaidín (EEZ-CSIC), Profesor Albareda 1, 18008 Granada, Spain. ${ }^{2}$ CIPAV TimacAGRO International-Roullier Group, Polígono

Arazuri-Orkoien, c/C no. 32, 31160-Orkoien, Navarra, Spain.

Received: 8 October 2013 Accepted: 23 January 2014

Published: 25 January 2014

\section{References}

1. Adesemoye AO, Torbert HA, Kloepper JW: Enhanced plant nutrient use efficiency with PGPR and AMF in an integrated nutrient management system. Can J Microbiol 2008, 54:876-886.

2. Adesemoye $\mathrm{AO}$, Torbert HA, Kloepper JW: Plant growth promoting rhizobacteria allow reduced application rates of chemical fertilizers. Microb Ecol 2009, 58:921-929.

3. Adesemoye $A O$, Kloepper J: Plant-microbes interactions in enhanced fertilizer-use efficiency. Appl Microbiol Biot 2009, 85:1-12.

4. Berg G: Plant-microbe interactions promoting plant growth and health: perspectives for controlled use of microorganisms in agriculture. Appl Microbiol Biot 2009, 84:11-18.

5. Gray EJ, Smith DL: Intracellular and extracellular PGPR: commonalities and distinctions in the plant-bacterium signalling processes. Soil Biol Biochem 2005, 37:395-412.

6. Emmerling C, Schloter M, Hartmann A, Kandeler E: Functional diversity of soils organisms: a review of recent research activities in Germany. J Plant Nutr Soil Sci 2002, 165:408-420.

7. Böhme L, Böhme F: Soil microbiological and biochemical properties affected by plant growth and different long-term fertilization. Eur J Soil Biol 2006, 42:1-12

8. Lugtenberg B, Kamilova F: Plant growth-promoting rhizobacteria. Annu Rev Microbiol 2009, 63:541-556.

9. Arzanesh MH, Alikhani HA, Khavazi K, Rahimian HA, Miransari M: Wheat (Triticum aestivum L.) growth enhancement by Azospirillum spp. under drought stress. World J Microbiol Biot 2011, 27:197-205.

10. Kende H, Zeevaart JAD: The five "classical" plant hormones. Plant Cell 1997, 9:1197-1210

11. Taiz L, Zeiger E: Plant Physiology. 2nd edition. Sunderland, Mass: Sinauer Associates; 1998.

12. Babaloa OO: Beneficial bacteria of agricultural importance. Biotechnol Lett 2010, 32:1559-1570

13. Pilet PE, Chanson A: Effect of abscisic acid on maize root growth: a critical examination. Plant Sci Lett 1981, 21:99-106.

14. Pilet PE, Saugy M: Effect on root growth of endogenous and applied IAA and ABA: a critical reexamination. Plant Physiol 1987, 83:33-38.

15. Quarrie SA: Use of Genotypes Differing in Endogenous Abscisic Acid Levels in Studies of Physiology and Development. In Hormone Action in Plant Development-a Critical Appraisal. Edited by Hoad GV, Lenton JR, Jackson MB, Atkin RK. London: Butterworths; 1987:89-105.

16. Tuomi T, Rosenquist H: Detection of abscisic, gibberellic and indole-3acetic acid from plant and microbes. Plant Physiol Biochem 1995, 33:725-734 
17. Karadeniz A, Topcuoglu SF, Inan S: Auxin, gibberellin, cytokinin and abscisic acid production in some bacteria. World J Microbiol Biotechnol 2006, 22:1061-1064.

18. Martellet C, Fett-Neto A: Role of auxin and its modulators in the adventitious rooting of Eucalyptus species differing in recalcitrance. Plant Growth Regul 2005, 45:1-10.

19. Nakayama T, Homma Y, Hashidoko Y, Mitzutani J, Tahara S: Possible role of xanthobaccins produced by Stenotrophomonas spstrain sB-K88 in suppression of sugar beet damping-off disease. Appl Environ Microbiol 1999, 65:4334-4339.

20. Vespermann A, Kai M, Piechulla B: Rhizobacterial volatiles affect the growth of fungi and Arabidopsis thaliana. Appl Environ Microbiol 2007, 73:5639-5641.

21. Jiang F, Chen L, Belimov AA, Shaposhnikov Al, Gong F, Meng X, Hartung W, Jeschke DW, Davies WJ, Dodd IC: Multiple impacts of the plant growthpromoting rhizobacterium Variovorax paradoxus $5 \mathrm{C}-2$ on nutrient and ABA relations of Pisum sativum. J Exp Bot 2012, 63:6421-6430.

22. Netting AG, Theobald JC, Dodd IC: Xylem sap collection and extraction methodologies to determine in vivo concentrations of $A B A$ and its bound forms by gas chromatography-mass spectrometry (GC-MS). Plant Methods 2012, 8:11

23. Herde O, Pena-Cortes $H$, Willmitzer L, Fisahn J: Stomatal responses to jasmonic acid, linolenic acid and abscisic acid in wild-type and ABA deficient tomato plants. Plant, Cell \& Environment 1997, 20:136-141.

24. Marulanda-Aguirre A, Azcon R, Ruiz-Lozano JM, Aroca R: Differential effects of a Bacillus megaterium strain on Lactuca sativa plant growth depending on the origin of the arbuscular mycorrhizal fungus coinoculated: Physiologic and biochemical traits. J Plant Growth Regul 2008, 27:10-18.

25. Marulanda A, Azcón R, Chaumont F, Ruiz-Lozano JM, Aroca R: Regulation of plasma membrane aquaporins by inoculation with a Bacillus megaterium strain in maize (Zea mays L.) plants under unstressed and salt-stressed conditions. Planta 2010, 232:533-543.

26. Marulanda A, Barea JM, Azcón R: Stimulation of plant growth and drought tolerance by native microorganisms (AM fungi and bacteria) from Dry environments: mechanisms related to bacterial effectiveness. J Plant Growth Regul 2009, 28:115-124.

27. Bacaicoa E, Mora V, Zamarreño AM, Fuentes M, Casanova E, García-Mina JM: Auxin: A major player in the shoot-to-root regulation of root Fe-stress physiological responses to Fe deficiency in cucumber plants. Plant Physiol Biochem 2011, 49:545-556.

28. Mora V, Baigorri R, Bacaicoa E, Zamarreño AM, García-Mina JM: The humic acid-induced changes in the root concentration of nitric oxide, IAA and ethylene do not explain the changes in root architecture caused by humic acid in cucumber. Environ Exp Bot 2012, 76:24-32

29. Porcel R, Barea JM, Ruiz-Lozano JM: Antioxidant activities in mycorrhizal soybean plants under drought stress and their possible relationship to the process of nodule senescence. New Phytol 2003, 157:135-143.

30. Kay R, Chau A, Daly M: Duplication of CaMV 35 S promoter sequences creates a strong enhancer for plants genes. Science 1987, 236:1299-1302.

31. Livak KJ, Schmittgen TD: Analysis of relative gene expression data using real-time quantitative PCR and the $2^{-\Delta \Delta C t}$ method. Methods 2001, 25:402-408

32. Bhattacharyya PN, Jha DK: Plant growth-promoting rhizobacteria (PGPR): emergence in agriculture. World J Microbiol Biotechnol 2012, 28:1327-1350.

33. Dodd IC, Zinovkina NY, Safronova VI, Belimov AA: Rhizobacterial mediation of plant hormone status. Ann Appl Biol 2010, 157:361-379.

34. Herrera-Medina MJ, Steinkellner S, Vierheilig H, Ocampo Bote JA, García Garrido JM: Abscisic acid determines arbuscule development and functionality in the tomato arbuscular mycorrhiza. New Phytol 2007, 175:554-564.

35. Taylor IB, Linforth RS, Al-Naieb RJ, Bowman WR, Marples BA: The wilty tomato mutants flacca and sitiens are impaired in the oxidation of ABA-aldehyde to ABA. Plant, Cell \& Environment 1988, 11:739-745.

36. Schwartz SH, Qin X, Zeevaart JAD: Elucidation of the indirect pathway of abscisic acid biosynthesis by mutants, genes and enzymes. Plant Physiol 2003, 131:1591-1601.

37. Cornish K, Zeevaart JAD: Phenotypic expression of wild-type tomato and three wilty mutants in relation to abscisic acid accumulation in roots and leaflets of reciprocal grafts. Plant Physiol 1988, 87:190-194.
38. Sagi M, Scazzocchio C, Fluhr R: The absence of molybdenum cofactor sulfuration is the primary cause of the flacca phenotype in tomato plants. Plant J 2002, 31:305-317.

39. Sharp RE, LeNoble ME, Else MA, Thorne ET, Gherardi F: Endogenous ABA maintains shoot growth in tomato independently of effects on plant water balance: evidence for an interaction with ethylene. J Exp Bot 2000, 51:1575-1584

40. Munns R, Cramer GR: Is coordination of leaf and root growth mediated by abscisic acid? Opinion. Plant Soil 1996, 185:33-49.

41. Beaudoin N, Serizet C, Gosti F, Giraudat J: Interactions between abscisic acid and ethylene signaling cascades. Plant Cell 2000, 12:1103-1115.

42. Anderson JP, Badruzsaufari E, Schenk PM, Manners JM, Desmond OJ, Ehlert C, Maclean DJ, Ebert PR, Kazan K: Antagonistic interaction between abscisic acid and jasmonate-ethylene signaling pathways modulates defense gene expression and disease resistance in Arabidopsis. Plant Cell 2004, 16:3460-3479.

43. Martín-Rodríguez JA, León-Morcillo R, Vierheilig H, Ocampo JA, LudwigMüller J, García-Garrido JM: Ethylene-dependent/ethylene-independent ABA regulation of tomato plants colonized by arbuscular mycorrhiza fungi. New Phytol 2011, 190:193-205.

44. Xiong L, Zhu JK: Regulation of abscisic acid biosynthesis. Plant Physiol 2003, 133:29-36.

45. Robert-Seilaniantz A, Grant M, Jones JDG, Jonathan DG: Hormone crosstalk in plant disease and defense: more than just JASMONATE-SALICYLATE antagonism. Annu Rev Phytopathol 2011, 49:317-343.

46. Ward ER, Uknes SJ, Williams SC, Dincher SS, Wiederhold DL, Alexander DC, Ahlgoy P, Metraux JP, Ryals JA: Coordinate gene activity in response to agents that induce systemic acquired-resistance. Plant Cell 1991, 3:1085-1094.

47. Ryals JA, Neuenschwander UH, Willits MG, Molina A, Steiner HY, Hunt MD: Sistemic acquired resistance. Plant Cell 1996, 8:1809-1819.

48. Durrant WE, Dong X: Systemic acquired resistance. Annu Rev Phytopathol 2004, 2:185-209.

49. Eulgem T: Regulation of the Arabidopsis defense transcriptome. Trends Plant Sci 2005, 10:71-78.

50. Van de Mortel JE, De Vos RCH, Dekkers E, Pineda A, Guillod L, Bouwmeester K, Van Loon JJA, Dicke M, Raaijmakers JM: Metabolic and transcriptomic changes induced in Arabidopsis by the rhizobacterium Pseudomonas fluorescens SS101. Plant Physiol 2012. doi:10.1104/pp.112.207324.

51. Mauch-Mani B, Mauch F: The role of abscisic acid in plant-pathogen interactions. Curr Opin Plant Biol 2005, 8:409-414.

52. Lenoble ME, Spollen WG, Sharp RE: Maintenance of shoot growth by endogenous $A B A$ : genetic assessment of the involvement of ethylene suppression. J Exp Bot 2004, 55:237-245.

53. Spollen WG, LeNoble ME, Samuels TD, Bernstein N, Sharp RE: Abscisic acid accumulation maintains maize primary root elongation at low water potentials by restricting ethylene production. Plant Physiol 2000, 3:967-976.

54. Van Loon LC, Van Strien EA: The families of pathogenesis-related proteins, their activities, and comparative analysis of PR-1 type proteins. Physiol Mol Plant Pathol 1999, 55:85-97.

55. Zamioudis C, Pieterse CM: Modulation of host immunity by beneficial microbes. Mol Plant Microbe In 2012, 25:139-150.

56. De Torres ZM, Bennett MH, Truman WH, Grant MR: Antagonism between salicylic and abscisic acid reflects early host-pathogen conflict and moulds plant defense responses. Plant J 2009, 59:375-386.

57. Fan J, Hill L, Crooks C, Doerner P, Lamb C: Abscisic acid has a key role in modulating diverse plant-pathogen interactions. Plant Physiol 2009, 150:1750-1761.

58. Li L, Zhu B, Yang P, Fu D, Zhu Y, Luo Y: The regulation mode of RIN transcription factor involved in ethylene biosynthesis in tomato fruit. J Sci Food Agric 2011, 91:1822-1828.

doi:10.1186/1471-2229-14-36

Cite this article as: Porcel et al:: Involvement of plant endogenous ABA in Bacillus megaterium PGPR activity in tomato plants. BMC Plant Biology $201414: 36$ 